\title{
Postoperative analgesia in a patient with knee surgery - use of a single puncture SOFT block
}

\author{
S Parthsarathy ${ }^{1}$, Reesha Joshi ${ }^{* *}$ \\ Professor $^{l}$, Senior Resident ${ }^{2}$, Department of Anaesthesiology, Mahatma Gandhi Medical College and \\ Research Institute, Sri Balaji Vidyapeeth University, Pillayarkuppam, Puducherry 607402, India.
}

\begin{abstract}
Postoperative analgesia after knee surgeries requires multiple nerve blocks. A twenty nine year old ASA I female was posted for arthroscopic anterior cruciate ligament repair. The procedure was done under spinal anaesthesia with $3 \mathrm{ml}$ of $0.5 \%$ hyperbaric bupivacaine and $30 \mu \mathrm{g}$ of preservative free clonidine. At the end of the surgery which lasted for 140 minutes, a single puncture access to all the nerves (sciatic, femoral and obturator- SOFT block) was done just at the inguinal region using ultrasound guidance. The blockade of all the nerves was confirmed after the complete recovery of spinal anaesthesia in the other leg. The analgesia lasted for 15 hours after the spinal recovery. Complete recovery from block was ensured as the block was administered with spinal anaesthesia to rule out any form of nerve injury.
\end{abstract}

Keywords: post-operative pain; knee; nerve block

\section{Introduction}

With regard to the neuronal anatomy and clinical experience, the blockade of sciatic, obturator and femoral nerves seems to be an effective block and may be a promising method to provide adequate analgesia for surgical procedures of knee. ${ }^{1}$ Conventionally this would require a change in positioning of the patient, probe and needle, which could cause discomfort for the patient and be time consuming. ${ }^{2}$ We present a case report where a relatively new block called SOFT block (Sciatic, obturator and femoral nerve block technique) was used for analgesia after surgical procedure of the knee to manage postoperative pain with a single puncture.

\section{Case history}

A 29-year old, $57 \mathrm{~kg}$ female patient with left anterior cruciate ligament tear following a road traffic accident was posted for arthroscopic anterior cruciate ligament reconstruction with hamstring graft. Her general physical and systemic examination including airway and spine were unremarkable and all investigations were within

\section{*Correspondence: Reesha Joshi \\ E mail: reesha.joshi@gmail.com}

https://orcid.org/0000-0002-5674-2228

Received: 20/08/2018

Accepted:14/11/2018

DOI: http:/doi.org/10.4038/slja.v27i1.8371

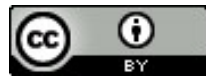

normal limits.

The procedure was completed with full monitoring under subarachnoid block with $3 \mathrm{ml}$ of $0.5 \%$ bupivacaine with $30 \mathrm{mcg}$ clonidine in 140 minutes. In view of the braces applied up to mid-thigh we had access to the upper thigh only.

Hence, we planned for a relatively new block called SOFT block in the inguinal region to provide effective early postoperative analgesia. A preparation of $0.25 \%$ bupivacaine was made. A $23 \mathrm{G} 90 \mathrm{~mm}$ in length Quincke needle (BD spinal needle) was used. A high frequency linear ultrasonography probe $(15-6 \mathrm{MHz}, 50 \mathrm{~mm})$ connected to the Ultrasound (Sonosite X-porte, Fujifilm) was positioned in the inguinal region with the patient in the supine position. With the help of the probe femoral vein, femoral artery and femoral nerve were identified. Complying with aseptic conditions, the needle was inserted in plane just medial to the femoral vein and advanced just below and parallel to the skin laterally to reach the femoral nerve where $10 \mathrm{ml}$ of the local anaesthetic was deposited with intermittent aspiration (Figure 1 (1)). With the needle in the same position the probe was repositioned medially and superior to the needle and tilted cranially. After identifying the pectineus muscle, the needle was withdrawn to the subcutaneous plane and redirected out-of-plane to lie deep to the pectineus and $10 \mathrm{ml}$ of local anaesthetic was deposited here to block the obturator nerve. (Figure 1 (2)) Lastly, a low frequency curvilinear ultrasound probe $(5-2 \mathrm{MHz}$, 
$60 \mathrm{~mm}$ ) was placed vertically inferior to the needle. The sciatic nerve was identified to lie longitudinally below the inferior border of the quadratus femoris muscle which appears as a "lesser than" sign. However, this time the needle was again inserted in-plane below the quadratus femoris and $20 \mathrm{ml}$ of local anaesthetic was injected here (Figure 1(3) and Figure 2). The whole procedure lasted less than five minutes. We waited for the complete recovery of spinal anaesthesia in the other leg to verify and establish the loss of pin prick in the femoral and sciatic nerve dermatomes. The adduction was very weak in the blocked leg which demonstrated obturator nerve blockade.

Postoperatively the patient was prescribed tramadol $50 \mathrm{mg}$ i.v. on demand. The patient had sensory and motor block for 12 hours and effective analgesia for 15 hours after the complete recovery from spinal local anaesthetic drug. As the block was administered with the patient under neuraxial anaesthesia, we ensured recovery from the block without any possible nerve injury.

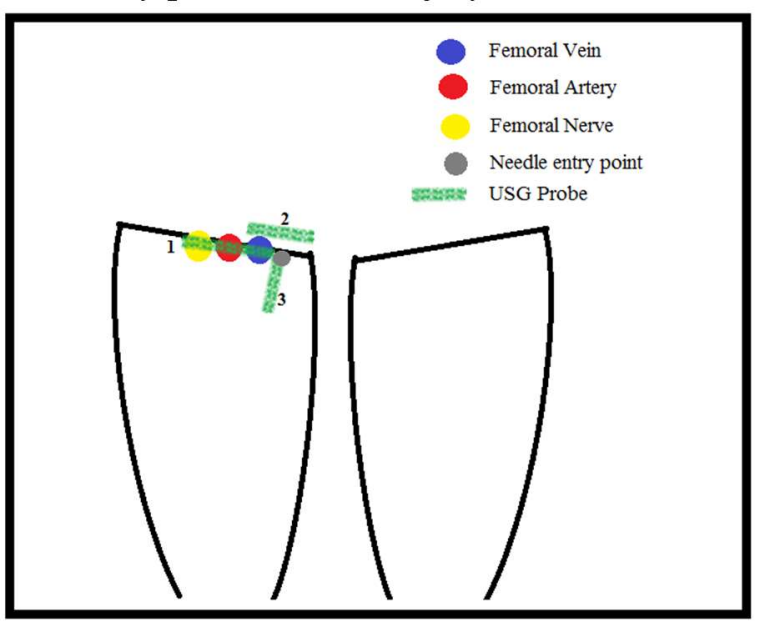

Figure 1. Positioning of the ultrasound probe at various locations for the SOFT block.

\section{Discussion}

Peripheral nerve blocks have been proven to improve postoperative analgesia which is devoid of side effects of central neuraxial blockade like urinary retention, hypotension, and epidural hematoma; and also provides better patient satisfaction and rehabilitation compared with IV narcotic drugs for knee and below knee procedures. ${ }^{3,4}$
Ultrasound-guided techniques have facilitated the anaesthesiologists to reduce the dose of local anaesthetic drugs, allowing combined or multiple blocks. $^{5}$

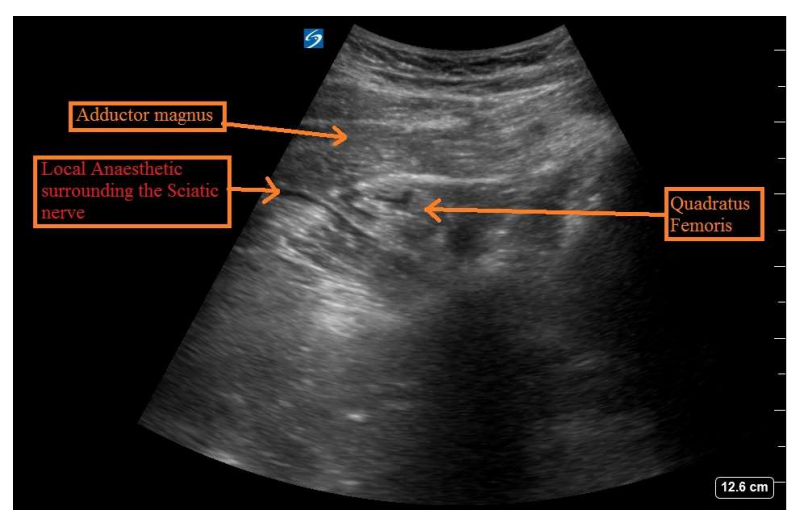

Figure 2. Sciatic nerve is surrounded by local anaesthetic deposited in the third part of the SOFT block.

The knee is supplied by branches from the nerve to vastus medialis, saphenous nerve, anterior and posterior divisions of the obturator nerve and the sciatic nerve (tibial and the peroneal components). ${ }^{6,7}$ Sciatic, obturator and femoral nerve blocks are preferred in surgical procedures of the lower limb for post-operative analgesia. ${ }^{1}$ Various studies have concluded that the combination of these blocks improves the postoperative analgesia significantly. ${ }^{8,9}$ However, combining these blocks needs a change of position, causing discomfort and logistic difficulties in trauma patients, apart from being time consuming. A single injection technique to block all these nerves can provide ease of practice. We have used a relatively new technique of blocking all three nerves in a single puncture, which requires less time, simple position and provided adequate analgesia. Our block was completed within five minutes in the supine position.

A study was conducted on 50 patients with torn knee ligaments where SOFT block was given for anaesthesia and they have reported the success to be comparable to blocking individual nerves while being less time consuming (less than 25 mins) and more comfortable to the patients. ${ }^{10}$

As administration of nerve blocks with already established spinal anaesthesia is prone to nerve injuries $^{5}$, we followed up the case for one week to 
Joshi et al. Sri Lankan Journal of Anaesthesiology: 27(1):83-85(2019)

rule out any such complication. As high-volume blocks need prior calculation of toxic dose we were particular about the dilution and administration of bupivacaine.

\section{Conclusion}

Single point, supine block of femoral, obturator, and sciatic nerve is a viable post-operative analgesic option in patients undergoing surgical procedures of the knee.

\section{References}

1. Taha AM, Abd-Elmaksoud AM. Arthroscopic medial meniscus trimming or repair under nerve blocks: which nerves should be blocked? Saudi J Anaesth 2016;10:283-7. https://doi.org/10.4103/1658-354x.174912

2. Fanelli G, Casati A, Garancini P, Torri G. Nerve stimulator and multiple injection technique or upper and lower limb blockade: failure rate, patient acceptance and neurologic complications. Study Group on Regional Anesthesia. Anesth Analg 1999;88:847-52.https://doi.org/10.1213/00000539199904000-00031

3. Capdevila X, Barthelet Y, Biboulet P, Rickwaert Y, Ruiovitch J, d'Athis F. Effects of perioperative analgesic technique on the surgical outcome and duration of rehabilitation after major knee surgery. Anesthesiology. 1999;91(1):8-15.

https://doi.org/10.1097/00000542-199907000-00006

4. Singelyn FJ, Deyaert M, Jorist D, Pendeville E, Gouverneur JM. et al. Effects of intravenous patient-controlled analgesia with morphine, continuous epidural analgesia, and continuous threein-one block on postoperative pain and knee rehabilitation after unilateral total knee arthroplasty. Anesth Analg. 1998;87(1):88-92

.https://doi.org/10.1213/00000539-19980700000019

5. J. M. Neal, R. Brull, J. L. Horn et al. The Second American Society of Regional Anesthesia and Pain Medicine evidence-based medicine assessment of ultrasound-guided regional anesthesia: executive summary. Regional Anesthesia and Pain Medicine. 2016;41(2):181-194.

https://doi.org/10.1097/aap.0000000000000331

6. Burckett-St Laurant D, Peng P, Giron Arango L, Niazi $\mathrm{AU}$, Chan VW, Agur A, et al. The nerves of the adductor canal and the innervations of the knee: Ananatomic study. Reg Anesth Pain Med. 2016;41(3):321-7. https://doi.org/10.1097/aap.0000000000000389

7. Dello AL. Partial Knee Joint Denervation for Knee Pain: A Review. Orthop Muscul Syst. 2014;3:167. https://doi.org/10.4172/2161-0533.1000167
8. Abdallah FW, Whelan DB, Chan VW, Prasad GA, Edersby RV, Theodoropolous J, et al. Adductor Canal Block Provides Non-inferior Analgesia and Superior Quadriceps Strength Compared with Femoral Nerve Block in Anterior Cruciate Ligament Reconstruction. Anesthesiology. 2016;124:1053-64. https://doi.org/10.1097/aln.0000000000001045

9. Grape S, Kirkham KR, Baeriswyl M, Albrecht E. The analgesic efficacy of sciatic nerve block in addition to femoral nerve block in patients undergoing total knee arthroplasty: a systematic review and meta-analysis. Anaesthesia.2016;71(10):1198209.https://doi.org/10.1111/anae.13568

10. Taha AM, Darwich N. SOFT (Sciatic, obturator and femoral nerve block technique): a single-puncture, sole anesthetic for knee surgery. Can J Anesth 2017; 64: 1279-81.

https://doi.org/10.1007/s12630-017-0947-4 